\title{
HOW TO DEVELOP OPEN SOURCE SYSTEMS EXPERTISE
}

\author{
Marek PARALIČ́ $\check{C}^{*}$ Peter BEDNÁR ${ }^{* *}$ \\ *Department of Computers and Informatics, Faculty of Electrical Engineering and Informatics, \\ Technical University of Košice, Letná 9, 04200 Košice, Slovak Republic, tel.: +42155602 2550, e-mail: marek.paralic@tuke.sk \\ ${ }^{* *}$ Department of Cybernetics and Artificial Intelligence, Faculty of Electrical Engineering and Informatics, \\ Technical University of Košice, Letná 9, 04200 Košice, Slovak Republic
}

\begin{abstract}
In this paper we describe a unique way for developing open source systems expertise that was gained by students in national and international teams. All activities are performed in context of Erasmus Intensive Programme project named "Developing open source system expertise in Europe". Altogether 70 students from 7 European countries work during one semester on different projects, focused on various open source systems. Project topics range from network management solutions, via enterprise content management, business process management, image recognition, to voting systems with mobile clients - to mention at least some of them. All seven participating universities bring together their knowledge and experience in specific open source systems and transfer them into 7 projects. Each project solution consists of the analysis and design phase that is carried out by national teams at home universities and the implementation phase that is carried out by international teams during the two-week intensive course.
\end{abstract}

Keywords: open source system, international mentored teamwork, Erasmus Intensive Programme, IP DOSSEE

\section{INTRODUCTION}

Developing open source system expertise in Europe (DOSSEE) is an Erasmus Intensive Programme ${ }^{1}$ (IP) project that focuses on sharing and exchanging knowledge and skills in open source software systems between lecturers and students from seven European countries. The participating universities are Helsinki Metropolia University of Applied Sciences (Finland), FH JOANNEUM - University of Applied Sciences (Austria), Universidad de Alcala (Spain), Technical University of Košice (Slovakia), Transport and Telecommunication Institute (Latvia), University Joseph Fourier (France) and Technical University of Denmark (Denmark).

The aim of this IP is to exchange knowledge of and experience in local methods and techniques in the field of open source software knowledge in ICT. The way how to achieve this is to engage a group of European students and lecturers in a conjoint explorative investigation of contemporary technologies of open source software systems. The target group consists of Bachelor level European engineering students who are interested in learning the innovative use of open source software based information systems in business cases and develop new skills based on the various national approaches in open source software systems and techniques.

As an expected outcome, the participating students will become competent in business orientation of open source software related technologies and methods in a multidisciplinary environment. They gain soft skills such as communication, teamwork in international frameworks and some of them also in team leadership, and apply these to the development of information systems and service provision in business cases. All the developed material is available online in a Wiki system, shared with by partners and offered to other institutions.

IP DOSSEE course is a part of the study curricula at the participating universities and if successfully completed by students, they earn 5 ECTS credits.
The rest of the paper is structured as follows. In the section 2 the overall IP DOSSEE development process is described. In the sections 3 and 4 two realizations of the IP DOSSEE course are described (mainly there are characterized the projects mentored by the Technical University of Košice). In the section 5 are summarized the results based on detailed questionnaires filled out by all project participants and also our experience in this type of creative educational work. Section 6 then concludes our paper.

\section{DOSSEE DEVELOPMENT PROCESS}

The workload of the students is split into two approximately equal parts - the home and the international one. During the home part students work in a national team of ten students that is mentored by two or three lecturers. The result of this phase is a technical plan of the selected project that will be implemented during the international phase by an international team of students. The work during the home phase is carried out during three months and takes approximately 80 hours per student.

The international part is carried out by international teams of students, where all proposed projects are implemented according to proposed technical plans. From the original national team only two students - team leaders - continue with the work at the proposed and in the technical plan described project.

The final assessment of students in the course consists of three parts ([1]):

- Assessment of the preliminary work at the home university. This part is done by the lecturers in the home universities and is mostly based on an evaluation of the developed technical plan.

- Peer Evaluation of the team members. All team members within a team assess each other (including themselves). 
- Team evaluation. Each team assesses the other teams (including their own team).

Grades are based on an overall assessment of these parts. Students are graded individually. Each part of the above listed evaluation points counts $1 / 3$ of the final grade.

\subsection{The home part}

The home part begins with the selection of open source technologies focus for ongoing course's run and this decision is competence each university. Thereafter 10 students (per university) who are interested in defined topics and also in the IP DOSSEE style of work are selected. Students together with lecturers propose the specific project on a consensual base. After short introduction into the selected technologies and available tools by lecturers, the work on technical plan begins. The work is done during the regularly team meetings, which are either mentored by lecturers or carried out by the students.

The result of the home phase is the technical plan that contains project brief description, analyses and design of proposed solution with utilization of UML diagrams, brief overview of utilized open source technologies and tools, as well as the time-plan for role and task distribution to the implementation team members. After finishing, the technical plans are made public to all students.

Two team members are selected for the role of team leader, who manage the implementation work during the second phase of the project in the international team of students.

\subsection{Intensive weeks - the international part}

During the home part the technical skills of students are gathered and consequently according to the project requirements the international teams are formed. The only exceptions are team leaders, who continue working at their original project, but in the role of responsible project managers.

After publishing the technical plans and international teams' membership, the second phase of the project begins. The international team members get to know each other via e-communication and prepare the detailed workplan for the two intensive weeks (e.g. by role assignment or technology pre-study).

The core of the IP DOSSEE course are two intensive weeks - ten 8-hours working days - during which all 70 students and approximately 20 lecturers meet at one place. Proposed projects are carried out by international teams in a form of mentored teamwork (lecturers guide the work on project proposed at their home university). At the beginning of the intensive weeks a general lecture on multicultural teamwork is given. In the realization in Alcala 2011 the Intercultural Ice-Breaker session was inserted [1], [2]. At the end of the intensive weeks each team gives one hour long presentation to demonstrate the project and its results and another 30 minutes are reserved for the discussion. As far as the team evaluation contributes to the final grading by $1 / 3$, final presentations are carefully followed by all teams and the discussion is rather open and fruitful.
All working activities are accompanied by social activities during the free time (participation for the students is not mandatory), that naturally help to overcome the national barriers.

\section{THE METROPOLIA CASE}

The first IP DOSSEE course took place in 2010 (15 26 March) at Helsinki Metropolia University of Applied Sciences in Espoo (Finland). The project proposed by the Technical University of Košice was focused at the area of Business Process Management (BPM). The team of the Technical University of Košice consisted of 11 students and two lecturers (authors of this paper). The reason for the additional place is that if some of the partners can not use all 10 student places, the unused places are distributed to other partners.

\subsection{Project proposal}

After discussions in the national team the scenario of the project facilitating the BPM technologies was identified as follows: "Development of a web-based, distributed system, which helps job office to facilitate cooperation process between employers and job seekers."

The job office offers its services as a business process that interconnects not only the registers of internal departments (EURES department - offers from countries of EU and Slovak RES department - offers from Slovakia), but connects also to Business register office (control of legality service) as an external service. Key actors of the proposed scenario with some of the utilized technologies are depicted at the Fig. 1.

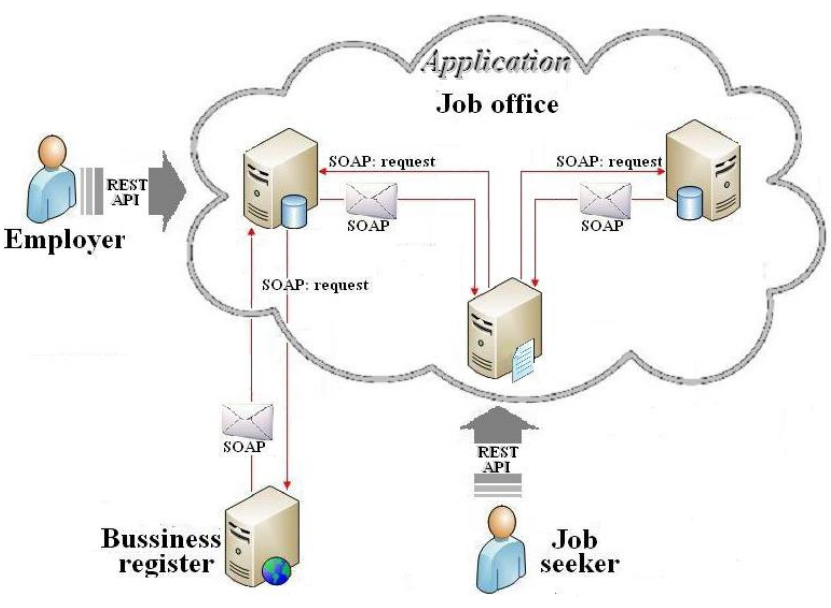

Fig. 1 Scenario overview for the TUKE project in the first realization of the IP DOSSEE course

\subsection{Analyses and design during the home phase}

The analyses started with the introductory presentation about the Enterprise Service Bus (ESB) technologies. Students then prepared their proposals for application, which were presented to others. They voted which proposal is the best and will be implemented. After this, each student selected one of the technology (XML technologies, SOAP/Web services, BPEL, etc.) and 
prepared document with a short description as well as a tutorial. Documents were then presented on workshops organized by students weekly During these workshops they also incrementally implemented the software prototype.

\subsection{Implementation in international team}

Work in the international team started with the short introductory presentation about the overall software architecture and the list of selected technologies. Subsequently, during the first intensive week, team leaders (supported and mentored by the lecturers) organized presentations and tutorials about the technologies for all students (i.e. they started with the lectures and implemented some simple examples). At the end of the first week, all students had overall knowledge about each technology needed for the implementation of the project. After the first week students divided themselves into groups. Each group was working on the part of the system according to the personal preferences and started the implementation. Though they spent a lot of time on lectures about technologies, during the second week they were able to implement a basic functionality of the system and prepare a final presentation of the work.

\section{THE ALCALA CASE}

The second IP DOSSEE course took place in 2011 (14 - 25 March) at Universidad de Alcala in Alcalá de Henares (Spain). This time the project proposed by the Technical university of Košice was focused on the area of Enterprise Content Management and its availability for mobile clients. The team of the Technical University of Košice consisted of 10 students and three lecturers (authors of this paper and Ing. Miroslav Biňas, PhD.).

\subsection{Project proposal}

The main topic for the Alcala was Content Management Systems (CMS) and Mobile Clients. The scenario proposed by national team supposed to present a Content Management System filled with a medical information. The target was its accessibility for a MediKit system. MediKit application is intended for doctors in order to consult medical cases. They can use the application by a mobile device in three ways: (a) create a case - doctors create a case by filling in a form with details about the case; (b) reply to a case - any doctor can reply to a case created by another doctor; and (c) search a case - doctor can search a case using tags, case name or find his own cases.

\subsection{Analyses and design during the home part}

Students divided themselves into two groups according to the selected technology, i.e. one group for the CMS part and one for the mobile client part with approximately the same number of members in each group. They started with the design of mock-up user interfaces and the definition of the supporting CMS services. All students participated on this initial design, especially on user interfaces, since this task does not require programming skills.
When the design was finished, students started development of the prototype. The work was organized in small groups around the few key persons with good technical skills. No one student had previous experience with the selected technologies, therefore an important part of the work was an individual study of documentation. Acquired knowledge was shared on the project wiki inside the Redmine ${ }^{2}$ system. Two introductory tutorials about Alfresco ${ }^{3}$ CMS and Android ${ }^{4}$ were presented by lecturers at the beginning of the home part. At the end of the home part, students provided integrated initial prototype of the software altogether with the supporting materials about the technologies and implementation. Finally, they decided who will be the team leader in the international team, where the main criterion was the level of technical skills and measure of the work done in project documentation.

\subsection{Implementation in international team}

The work in the international team started with the short introductory presentation of the software architecture and user interface mock-ups. Students then divided themselves according to the technology - one group was working on Alfresco CMS solution and one on Android client. Unfortunately, groups were very unbalanced, practically only two students (one team leader and one student with previous experience with Alfresco) were working on CMS part, and the rest of them were implementing Android client. Students were subsequently grouped according to the personal preferences into pairs, each working on one selected functionality. The development was coordinated by team leaders who also distributed work to groups. Last two days were dedicated to the final integration, testing and a preparation of the presentation.

\section{RESULTS AND LESSON LEARNED}

At the moment of writing this paper, two courses of IP DOSSEE were successfully finished and third one in Kapfenberg (Austria) is being prepared. The main motivations - developing open source systems expertise in Europe and improving the soft skills of participated students and lecturers, were in our opinion transformed in the praxis.

\section{Feedback based evaluation}

Let us first take a look at the carefully collected feedback from the students after finishing the last working day. The Table 1 contains the student evaluation about the implementation of the IP and the intensive weeks, Table 2 contains the answers to the question "What did you gain from the IP?". First table uses the scale 1-5, where 1 means worst and 5 means best. Second table contains number that represents percentage of students, who perceived given outcome as relevant. The "Other" benefits could specify students by own words and they mentioned among other things business contacts, new ideas, self confidence, teamwork experience, and leader skill

\footnotetext{
${ }^{2}$ http://www.redmine.org/

${ }^{3} \mathrm{http} / / / \mathrm{www}$. alfresco.com/

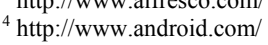


experience, stress management, wider perspectives/views of the world, fun.

Table 1 IP DOSSEE Student Feedback Comparison

\begin{tabular}{|l|c|c|}
\hline \multicolumn{1}{|c|}{$\begin{array}{c}\text { Evaluation of the } \\
\text { implementation of the IP }\end{array}$} & $\mathbf{2 0 1 0}$ & $\mathbf{2 0 1 1}$ \\
\cline { 2 - 3 } & average & average \\
\hline $\begin{array}{l}\text { Intensive weeks corresponded } \\
\text { with my expectations }\end{array}$ & 4,18 & 4,09 \\
\hline $\begin{array}{l}\text { Usefulness of the theoretical } \\
\text { content }\end{array}$ & 3,97 & 3,66 \\
\hline $\begin{array}{l}\text { Usefulness of the practical } \\
\text { assignments }\end{array}$ & 4,36 & 4,26 \\
\hline $\begin{array}{l}\text { Usefulness of the publishing } \\
\text { platform }\end{array}$ & 2,88 & 3,79 \\
\hline $\begin{array}{l}\text { Overall concept of the intensive } \\
\text { study program }\end{array}$ & 4,34 & 4,39 \\
\hline Evaluate your own contribution & 4,12 & 4,23 \\
\hline $\begin{array}{l}\text { Corresponded with own } \\
\text { expectations }\end{array}$ & 4,18 & 4,09 \\
\hline $\begin{array}{l}\text { Contacts with students } \\
\text { participating in the IP }\end{array}$ & 4,46 & 4,59 \\
\hline General grade of the IP & 4,32 & 4,49 \\
\hline
\end{tabular}

Table 2 IP DOSSEE benefits perceived by students

\begin{tabular}{|l|c|c|}
\hline \multicolumn{1}{|c|}{ IP DOSSEE benefits } & $\mathbf{2 0 1 0}$ & $\mathbf{2 0 1 1}$ \\
\cline { 2 - 3 } & average & average \\
\hline $\begin{array}{l}\text { New skills and theoretical } \\
\text { knowledge }\end{array}$ & $81,7 \%$ & $73,6 \%$ \\
\hline Better language skills & $76,1 \%$ & $79,2 \%$ \\
\hline New friends & $87,3 \%$ & $93,1 \%$ \\
\hline $\begin{array}{l}\text { Experience and knowledge of } \\
\text { different cultures }\end{array}$ & $78,9 \%$ & $86,1 \%$ \\
\hline Independence & $29,6 \%$ & $30,6 \%$ \\
\hline Life experience & $73,2 \%$ & $84,7 \%$ \\
\hline Credits & $53,5 \%$ & $58,3 \%$ \\
\hline Other & $26,8 \%$ & $22,2 \%$ \\
\hline
\end{tabular}

Original method for mediation of skills in open source systems as presented and applied in IP DOSSEE project suppose work on two potentially very different projects the one proposed in home part of the project and the second one implemented during the intensive weeks. Even if the students (with exception of two team leaders per project) do not have freedom to choose the project in second phase, the overall note for "Overall concept of the intensive study program" and "General grade of the IP" is very high $-4,39$ and 4,49 respectively.

Based on our experience in order to keep the motivation of the students high during the whole home phase (not only for those students aspiring to the team leader position), we include also the prototype implementation part in the home phase. This decision also came out as very helpful in situation, when the international team split into uneven parts (like in Alcala case). The part with fewer students was based on the prototype solution and the more popular part was during the implementation highly extended beyond the specification. For the third round of the IP DOSSEE students will also participate in the technology focus decision phase, as well as in the open source development tools selection phase.

Experiences gained during the prototype building help also the team leaders to propose feasible work-plan schedule and role division for the international team that implements the whole project. Balanced allocation of work during the intensive weeks is important even more than in a home phase, because membership in the international team is defined by the coordinator of the project based on student's technical skills and not on demand. By taking these aspects into account, the result according to the feedback is very positive - the "Usefulness of the practical assignments" is ranked by the average note 4,26 .

Another experience improved and developed during the project is the collaborative platform for the project design and implementation. In the first year the moodle ${ }^{5}$ system as open source Course Management System and Learning Management System were chosen. Moodle was perceived as a good platform for offering the theoretical content, but not suitable as a publishing platform ("Usefulness of the publishing platform" only 2,88). Second round of the IP DOSSEE project thereafter used combination of the open source systems MediaWiki ${ }^{6}$ and Redmine as a flexible project management web application that increases the "Usefulness of the publishing platform" evaluation to the note 3,79 .

\section{Knowledge sharing benefit}

Sharing knowledge about the particular open source solution had an important impact on the students work during all project phases. This sharing of useful implementation hints, experiences with the frameworks, etc., emerged not only within the team (national during the preparation of the project proposal or international during the project implementation) but also between the teams. For example, because of network limitation in METROPOLIA, all teams had to overcome the same technical problems with the networking, and since the project of Finish team was oriented towards the network configuration, they served as the network specialist for other teams.

\section{Experiences with teaching, leadership and work organization}

During preparation of the project proposal students organized tutorials and introductory presentations for their colleagues. Then during the work in an international team, team leaders had to explain the project objectives. Also they presented lecture materials about all technologies prepared during the project proposal phase. Team leaders had to face also problems with a motivation of team members. For example: if any members did not have particular technical skills required for implementation tasks, leaders had to find another team role suitable for them. Leaders were also responsible for organization of work and planning (many times they had to revise initial plans because of time limitations or technical difficulties).

\footnotetext{
${ }^{5}$ http://moodle.org/

${ }^{6} \mathrm{http}: / /$ www.mediawiki.org/wiki/MediaWiki
} 


\section{CONCLUSIONS}

In comparison to our previous experiences in elearning domain [3], [4], [5], the IP DOSSEE project represent a unique way for developing open source systems expertise that could gain students in national and international teams. It combines open source application as a target result, open source development tools usage, and open source tools for management and collaboration support. Thanks to the Erasmus Intensive Programme it contains also the opportunity to gain important soft skills such as communication, teamwork in international frameworks and for some of the students also in team leadership during the two intensive weeks. In broader context it can be seen in conformance with the $\mathrm{CDIO}^{7}$ initiative that is an innovative educational framework for producing the next generation of engineers [2], [6]. The CDIO framework provides students with an education stressing engineering fundamentals set in the context of Conceiving — Designing — Implementing Operating real-world systems and products.

\section{ACKNOWLEDGMENT}

The work presented in this paper was supported by the project Developing Open Source System Expertise in Europe, an Erasmus Intensive Programme under the Lifelong Learning Programme, agreement numbers IP242663/3/1/371/09 and 2010-1-FI1-ERA10-03174.

\section{REFERENCES}

[1] NYBORG, M. - GUSTAFSSON, F. CHRISTENSEN, J. E.: Developing Open Source Systems Expertise in Europe (DOSSEE), Seventh International CDIO Conference, Technical University of Denmark, Copenhagen, ISBN 978-87-985272-6-8, pp. 1013-1024, June 2011.

[2] CHRISTENSEN, J. E. - KARHU, M. CHRISTENSEN, C.: Teaching interpersonal skills in international design-build course, Seventh International CDIO Conference, Technical University of Denmark, Copenhagen, ISBN 978-87-985272-6-8, pp. 602-617, June 2011.

[3] KERER, C. - REIF, G. - GSCHWIND, T. KIRDA, E. - KURMANOWYTSCH, R. PARALIČ, M.: ShareMe: Running a Distributed
Systems Lab for 600 Students With Three Faculty Members, IEEE Transactions on Education, Vol. 48, No. 3, pp. 430-437, 2005.

[4] PARALIČ, J. - BABIČ, F. - WAGNER, J. BEDNÁR, P. - PARALIČ, M.: KP-lab system for the support of collaborative learning and working practices, based on trialogical learning, Informatica: an International Journal of Computing and Informatics, Vol. 34, No. 3, pp. 341-351, 2010.

[5] BABIČ, F. - PARALIČ, J. - RACEK, M. WAGNER, J.: Knowledge Practices Laboratory, Ambient Intelligence and Smart Environments, IOS Press, Vol. 1, ISSN 1875-4163, pp. 42-49, 2009.

[6] KONTIO, J. - ROSLÖF, J. - EDSTRÖM,K. Naumann, S. T. - HUSSMANN, P. M. - SCHREYNIEMENMAA, K. - KARHU, M.: Quality Assurance with CDIO self-evaluation - First results of a Nordic project, Seventh International CDIO Conference, Technical University of Denmark, Copenhagen, ISBN 978-87-985272-6-8, pp. 65-74, June 2011.

Received September 9, 2011, accepted December 2, 2011

\section{BIOGRAPHIES}

Marek Paralič received his Master degree in 1995 and his Ph.D. degree in 2002, both at the Technical University in Košice. Since 1996 he works as an assistant professor at the Department of Computers and Informatics, Technical University in Košice and since 2006 also researcher at the Centre for Information Technologies at the same university. His research interests currently are in the areas of distributed programming, agent-based technologies and service-oriented computing.

Peter Bednár received his Master degree in 2001 at the Technical University in Košice. Since 2005 he is working as a researcher in the Centre of Information Technologies, common workplace of Institute of Informatics, Slovak Academy of Sciences in Bratislava, and Technical University of Košice. His scientific research is focused on the areas of text mining, knowledge management, semantic technologies, eGovernment, and knowledge discovery. 